\title{
Influence of Listeria innocua on the growth of Listeria monocytogenes
}

\author{
Ana Carvalheira, Cátia Eusébio, Joana Silva, Paul Gibbs, Paula Teixeira * \\ CBQF/Escola Superior de Biotecnologia, Universidade Católica Portuguesa, R. Dr. António Bernardino de Almeida, 4200-072 Porto, Portugal
}

Keywords:

Growth and inhibition

Listeria monocytogenes

Listeria innocua

\begin{abstract}
A B S T R A C T
The growth of Listeria monocytogenes and Listeria innocua strains was monitored during this study: (i) in TSB-YE media and (ii) in a food matrix (pasteurized milk) according to the ISO 11290-1 methodology. Different inocula concentrations and mixtures were tested. The response was shown to be strain dependent. In TSB-YE the inhibition of a L. monocytogenes strain was observed in just one of the three mixtures (L. monocytogenes_1340 with L. innocua_11288) showing a reduction of $1.37 \mathrm{log} \mathrm{cfu} / \mathrm{ml}$ after $42.5 \mathrm{~h}$ and $1.85 \mathrm{log}$ after $66.5 \mathrm{~h}$ of incubation. In pasteurized milk the inhibition of L. monocytogenes by L. innocua was always observed when L. innocua was present in higher concentrations than $L$. monocytogenes. The reverse was also observed but only in one mixture (cocktail of six $L$. monocytogenes with $L$. innocua_2030c) when the initial concentration of L. monocytogenes was 100 times higher than L. innocua suggesting the phenomenon of quorum sensing. Furthermore, inhibitory activity was not caused by bacteriocins, and no correlation between the growth rate and inhibition was demonstrated.
\end{abstract}

\section{Introduction}

Listeria monocytogenes is an important foodborne pathogen which causes listeriosis, a serious invasive illness in humans (Farber \& Peterkin, 1991). Despite the low incidence, listeriosis is of considerable public health concern because it still represents a health risk due to its high mortality rate (30\%) within the risk groups: neonates, elderly people, pregnant women and immunocompromised individuals (Siegman-Igra et al., 2002).

L. monocytogenes has an ubiquitous distribution and a great ability to grow in a wide range of conditions, such as refrigeration temperatures, low $\mathrm{pH}$ and high salt concentration (Seeliger \& Jones, 1986; Grau \& Vanderlinde, 1992), that enables it to survive and grow in foods and food-processing environments, and overcome the multiple hurdles employed in food preservation and safety, increasing the risk of food contamination. Detection of $L$. monocytogenes is crucial within the food industry because consumption of contaminated raw and/or processed food products such as meat, poultry, seafood, dairy products and vegetables, is the cause of $99 \%$ of all listeriosis cases (Mead et al., 1999; Schlech, 2000).

The detection of $L$. monocytogenes usually involves selective enrichment procedures due to the high levels of background microflora that are normally present in food matrices and also because the presence of this microorganism in food is generally low, which exacerbates further analysis (Norton et al., 2001).

\footnotetext{
* Corresponding author. Tel.: +351 2255800 95; fax: +351225090351. E-mail address: pcteixeira@esb.ucp.pt (P. Teixeira).
}

Several research reports have demonstrated that the presence of Listeria innocua may mask L. monocytogenes, which could lead to a false negative result for the presence of $L$. monocytogenes (Cornu, Kalmokoff, \& Flandrois, 2002; Curiale \& Lewus, 1994; Petran \& Swanson, 1993).

Different explanations for this have been proposed, such as a more rapid growth advantage of L. innocua $\mathrm{cf}$. L. monocytogenes (Beumer, Giffel, Anthonie, \& Cox, 1996; Curiale \& Lewus 1994; Petran \& Swanson 1993), in contrast to inhibitory interspecies interactions which have been attributed to the production of bacteriocinlike agents (Besse, Audinet, Kérouanton, Collin, \& Kalmokoff, 2005; Cornu et al., 2002; Yokoyama, Maruyama, Katsube, \& Mikami, 2005). At the present time, both explanations remain unclear.

The majority of inhibitors may correspond to defective bacteriophage particles, also referred to as monocins (Curtis \& Mitchell, 1992; Zink, Loessner, \& Scherer, 1994), listeriocins (Lebek, Teysseire, \& Baumgartner, 1993; Ortel, 1989), or bacteriocin-like compounds (Curtis \& Mitchell, 1992; Yokoyama et al., 2005). However, there remains some confusion regarding inhibitory activities resulting from the production of bacteriocins among Listeria isolates (Zink, Loessner, \& Scherer, 1995).

Bacteriocin production within Listeria spp. may be important because the accompanying resistance phenotype could influence the susceptibility of these isolates to the presence of added or produced LAB bacteriocins (Eijsink, Skeie, Middelhoven, Brurberg, \& Nes, 1998; Song \& Richard, 1997). They could also indirectly enhance pathogenicity by allowing the competition and establishment of bacteriocin-producing isolates within mixed flora food systems. Moreover, if bacteriocins are produced among Listeria spp., these may represent new anti-Listeria inhibitors with poten- 
tial applications in food products. Therefore, there is currently much interest in the application of bacteriocins that demonstrate anti-Listeria properties for the inhibition of this pathogen in a variety of food products either through bacteriocin-producing cultures (Albano et al., 2008; Eppert, Valdés-Stauber, Götz, Busse, \& Scherer, 1997; Muriana, 1996; Winkowski, Crandall, \& Montville, 1993), or by the addition of pure or semi-pure bacteriocins (Davies, Bevis, \& Delves-Broughton, 1997; Muriana, 1996; Vigonolo et al., 1998; Albano et al., 2008).

The aim of this study was to evaluate the influence of L. innocua on the growth of L. monocytogenes determined by; (i) growth of these two species when grown individually and concurrently in a non-selective Listeria culture medium (TSB-YE); (ii) determination of $L$. monocytogenes recovery in the enrichment procedure according to ISO 11290-1 reference method in a food matrix, namely pasteurized milk; both systems were inoculated with different concentrations of both species and evaluated the impact of strain over-growth during each step of the enrichment process; and (iii) detection of any inhibitory activity produced by L. innocua against L. monocytogenes.

\section{Materials and methods}

\section{Cultures and preparation of inocula}

Different $L$. monocytogenes and L. innocua strains were used during this study: L. monocytogenes 1339, 1340, 1334, 1792, 999, 1336 (all from ESB, UCP culture collection) and L. innocua_2030c (Public Health Laboratory Services, London) and 11288 (National Collection of Type Cultures, UK; NCTC). Stock cultures were kept in Tryptone Soya broth with Yeast Extract 0.6\% w/v (TSB-YE, Lab M, UK) supplemented with $30 \%(\mathrm{w} / \mathrm{v})$ of glycerol at $-80^{\circ} \mathrm{C}$. Working cultures were sub-cultured twice in TSB-YE $(1 \% \mathrm{v} / \mathrm{v})$ incubated at $37^{\circ} \mathrm{C}$ for $24 \mathrm{~h}$, before use.

\section{Monitoring growth of L. monocytogenes and L. innocua strains individually}

For each culture, growth was determined using the Microplate Method. To each well of a sterile 96-well microtiter plate (Orange Scientific, Belgium), $200 \mu \mathrm{L}$ of TSB-YE were added and inoculated with $1 \%(\mathrm{v} / \mathrm{v})$ of each cell suspension obtained as described above, previously diluted in sterile Ringer solution to $10^{4} \mathrm{cfu} / \mathrm{ml}$ (for all the tested strains growth curves were previously determined, O.D. vs. cfu/ml; data not shown). Microplates were incubated at $30^{\circ} \mathrm{C}$ for $24 \mathrm{~h}$ and the Optical Density (O.D.) at $665 \mathrm{~nm}$ was registered at $30 \mathrm{~min}$ intervals by the Microplate Reader (Model 680, Bio-Rad). Three independent replicates of these assays were performed.

Monitoring growth of $L$. monocytogenes strains in the presence of $L$. innocua

The growth of different isolates of L. monocytogenes in the presence of $L$. innocua was evaluated during this study in different cocultures as described in Table 1 . In all the experiments, a positive control of each isolate was performed.
In non-selective medium

TSB-YE was inoculated with $1 \%(v / v)$ of each mixture (see Table 1) with an initial cell concentration of $10^{4} \mathrm{cfu} / \mathrm{ml}$ and incubated in a water bath (Julabo SW22, Germany) with agitation (70 rpm) for $72 \mathrm{~h}$ at $30^{\circ} \mathrm{C}$. At defined intervals aliquots of $1 \mathrm{ml}$ were collected for further enumeration. Two independent replicates of this assay were performed.

In food matrix artificially contaminated undergoing enrichment culturing

Pasteurized milk obtained from a retail establishment was artificially contaminated with strains of $L$. monocytogenes, $L$. innocua or both $(1 \% \mathrm{v} / \mathrm{v})$; cultures were grown at $37^{\circ} \mathrm{C}$ for $24 \mathrm{~h}$ in TSB-YE and suitably diluted as described in Table 2 . The subsequent analysis of the inoculated milk was performed according to the ISO 11290-1 method for enumeration of L. monocytogenes (Anonymous, 2004). At each defined interval, aliquots were taken for enumeration, such as immediately after the addition of Half Fraser broth (Merck, Germany) to the inoculated milk; after $24 \mathrm{~h}$ at $30^{\circ} \mathrm{C}$ in Half Fraser broth, and after a further $24 \mathrm{~h}$ and $48 \mathrm{~h}$ in Fraser broth (Merck) at $37^{\circ} \mathrm{C}$. Two independent replicates of this assay were performed.

\section{Enumeration}

Aliquots obtained as described above were serially diluted and plated using the drop counting technique onto the Agar Listeria Ottaviani Agosti plates (ALOA, AES Laboratories, France) and incubated at $37^{\circ} \mathrm{C}$ for $18-48 \mathrm{~h}$. The differentiation of L. monocytogenes and $L$. innocua was performed according to the presence of characteristic colonies in ALOA, namely blue green with halo in the case of $L$. monocytogenes and blue green without halo in the case of $L$. innocua.

\section{Detection of inhibitory activity produced by Listeria strains}

Listeria isolates were screened for the production of inhibitory activity such as bacteriocins, by the spot-on-lawn method. The cultures of $L$. innocua and $L$. monocytogenes obtained as described above, were evenly spread on plates of TSA-YE (Tryptone Soya Agar with Yeast Extract $0.6 \% \mathrm{w} / \mathrm{v})$ and drops $(10 \mu \mathrm{l})$ of the other species, respectively, were spotted on the lawns and incubated at $30^{\circ} \mathrm{C}$ for 24-48 h. Inhibition was considered positive if a translucent halo was observed around the spot.

\section{Statistical analysis}

All the experiments were repeated at least three times. An analysis of variance (one-way ANOVA) was performed to test significant effects of: (i) the survival of $L$. monocytogenes when $L$. innocua is present (ii) the survival of L. innocua when L. monocytogenes is present and (iii) the inoculum concentration of each Listeria strain in the mixture. All calculations were carried out using the software Kaleidagraph (version 4.04, Synergy Software, Reading, USA).

Table 1

Mixtures of Listeria monocytogenes and Listeria innocua strains.

\begin{tabular}{|c|c|}
\hline Mixture & \\
\hline 1 & Six strains of $L$. monocytogenes $(1339,1340,1334,1792,999,1336)$ and $L$. innocua_2030c \\
\hline 2 & L. monocytogenes_1339 and L. innocua_11288 \\
\hline 3 & L. monocytogenes_1340 and L. innocua_11288 \\
\hline
\end{tabular}


Table 2

Conditions used for artificial contamination of pasteurized milk.

\begin{tabular}{ll}
\hline Conditions & Inoculum \\
\hline 1 & L. monocytogenes $\left(10^{2} \mathrm{cfu} / \mathrm{ml}\right)$ and L. innocua $\left(10^{2} \mathrm{cfu} / \mathrm{ml}\right)$ \\
2 & L. monocytogenes $\left(10^{4} \mathrm{cfu} / \mathrm{ml}\right)$ and L. innocua $\left(10^{4} \mathrm{cfu} / \mathrm{ml}\right)$ \\
3 & L. monocytogenes $\left(10^{4} \mathrm{cfu} / \mathrm{ml}\right)$ and L. innocua $\left(10^{2} \mathrm{cfu} / \mathrm{ml}\right)$ \\
4 & L. monocytogenes $\left(10^{2} \mathrm{cfu} / \mathrm{ml}\right)$ and L. innocua $\left(10^{4} \mathrm{cfu} / \mathrm{ml}\right)$ \\
\hline
\end{tabular}

\section{Results and discussion}

Monitoring growth of L. monocytogenes and L. innocua strains individualy

The growth kinetics of all $L$. monocytogenes and $L$. innocua strains were previously evaluated by the microplate method. In fact, other authors have already described the success of the microplate method for studying growth kinetics compared to standard cultivation methods (Horáková, Greifová, Seemannová, Gondová, \& Wyatt, 2004).

Results were compared and analyzed according to the generation time, growth rate, lag and exponential phase duration and by the comparison of the differences between the initial and final O.D. of the growth curve (data not shown). According to our results, the growth rate varied according to the tested strain. Furthermore, L. monocytogenes_1339 showed the shortest generation time (119 min) followed by L. innocua_11288 (124 min), L. monocytogenes_1340 (130 $\mathrm{min})$ and L. innocua_2030c (167 min). Within these results, the mixtures of $L$. monocytogenes and $L$. innocua were selected for further studies.

Curiale and Lewus (1994) verified that in TSB-YE the generation times of L. innocua were longer than $L$. monocytogenes. However, they only used a single strain from each species and ignored the inter-strain variability. The work performed by Petran and Swanson (1993) and MacDonald and Sutherland (1994), used a range of strains; however, they did not find significant differences between the two species.

\section{Monitoring growth of $\mathrm{L}$. monocytogenes strains in the presence of} L. innocua

Table 1 describes the three different mixture conditions that were selected to evaluate the growth of $L$. monocytogenes in the presence of L. innocua. One of those conditions was performed with all the $L$. monocytogenes isolates since frequently the food products are contaminated with more than one strain of this pathogen (mixture 3, Table 1). The strains' behaviours were evaluated in a nonselective medium and in artificially contaminated milk, as discussed below.

It is widely accepted that $L$. innocua has an advantage over $L$. monocytogenes during enrichment culturing due to faster growth rates (Beumer et al., 1996; Curiale and Lewus, 1994) however, our results demonstrated that there were no absolute correlations between growth rates or inhibitory activity in terms of strain evolution during enrichment (data not shown).

In non-selective medium

In the case of mixtures 1 and 3 , strains of $L$. innocua had no influence on the growth of L. monocytogenes (data not shown). Concerning the mixture 2, a cell reduction of L. monocytogenes_1340 was observed when $L$. innocua_11288 was present (1.37 log after $42.5 \mathrm{~h}$ and $1.85 \mathrm{log}$ after $66.5 \mathrm{~h}$ of incubation) suggesting L. monocytogenes inhibition (Fig. 1). Besides the same initial numbers of both strains, the preferential growth of $L$. innocua, in our case, was not consistent with differences in generation times and growth rate. At the end of the normal enrichment period, the number of $L$. innocua cells exceeded the number of $L$. monocytogenes cells by at least 10 -fold.

Other studies, also evaluated the influence of $L$. innocua on the growth of L. monocytogenes; however, these studies were performed after the enrichment step described in the ISO methodology (Anonymous, 2004; Besse et al., 2005; Cornu et al., 2002; Yokoyama et al., 2005).

In the present study, it was demonstrated that even in a nonselective medium i.e. TSB-YE, it is possible to observe the inhibition of $L$. monocytogenes when $L$. innocua is present.

\section{In a food matrix artificially contaminated undergoing enrichment} culturing

Previously, Cornu et al. (2002) studied the influence of L. innoc$u a$ in the growth of L. monocytogenes; however, an initially high cell number $\left(10^{7}\right.$ cells $\left./ \mathrm{ml}\right)$ was used and that is not likely to occur in naturally contaminated food samples. Other authors, however, studied lower initial contamination levels but with the same inocula concentrations of $L$. monocytogenes and $L$. innocua (Besse et al., 2005; Yokoyama et al., 2005). The challenge of the current study is to evaluate the impact of lower initial contamination levels on inter-strain interaction when both strains are or not in the same cellular concentration.

Cocktail of six strains of L. monocytogenes with L. innocua_2030c.

At the same inoculum concentration (conditions 1 and 2 , Table 2$)$ there were no significant differences $(P>0.05)$ in the growth of the cocktail of $L$. monocytogenes when L. innocua_2030c was present and vice versa (Fig. 2). When different inoculum concentrations were tested, two situations were observed; (i) inhibition of the L. monocytogenes cocktail (decrease of $3.21 \mathrm{log}$ after $72 \mathrm{~h}$ ) when $L$. innocua was present in higher concentration $(P<0.05)$ and (ii) inhibition of L. innocua (decrease of $3.32 \mathrm{log}$ after $72 \mathrm{~h}$ ) when $L$. monocytogenes cocktail was present in higher cell numbers $(P<0.05)$ (Fig. 2$)$.

In the literature, only the inhibition of $L$. monocytogenes by $L$. innocua is discussed. However, in the present study the contrary was also demonstrated. A possible explanation could be 'quorum sensing' (QS), that is a regulation of gene expression in response to cell population density, in this case resulting in an inhibition of growth of a population of bacteria when a certain number are present, usually ca. $10^{6} \mathrm{cfu} / \mathrm{ml}$. QS occurs by recognition of a concentration of a 'quorum compound' in pure cultures and in mixed cultures of similar organisms (e.g. E. coli and Salmonella spp.), and a

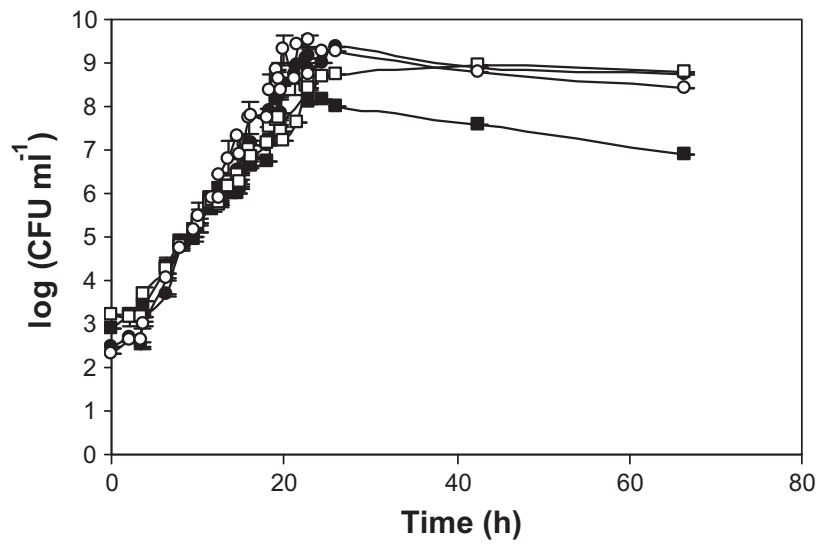

Fig. 1. Growth curves in TSB-YE of L. monocytogenes_1340 with L. innocua_11288. Error bars indicate variability between assays (-L. innocua in mixture; $\bigcirc$-control of L. innocua; -L. monocytogenes in mixture; $\square$-control of L. monocytogenes). 


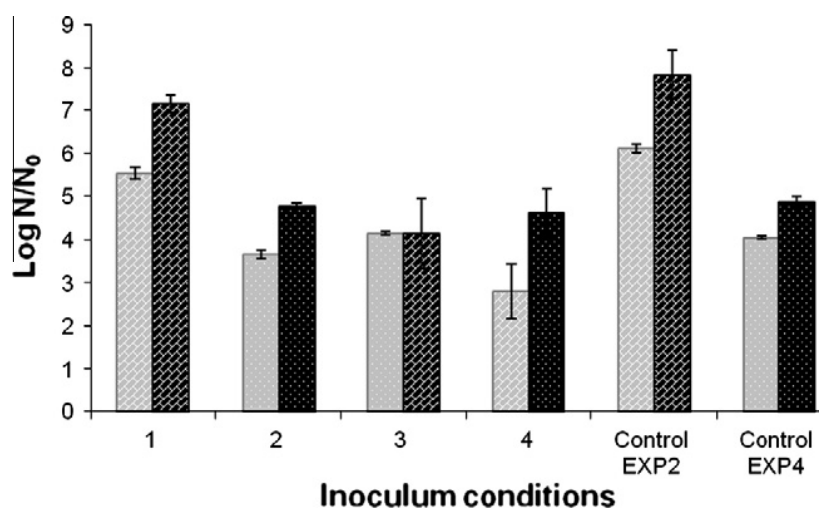

Fig. 2. Monitoring the number of viable cells in pasteurized milk: combination of all six strains of $L$. monocytogenes with $L$ innocua_2030c. 2 . monocytogenes $\left(10^{2} \mathrm{cfu} / \mathrm{ml}\right) ; \quad$ L. monocytogenes $\left(10^{4} \mathrm{cfu} / \mathrm{ml}\right) ;$ L. innocua $\left(10^{2} \mathrm{cfu} / \mathrm{ml}\right) ; \mathrm{L}$. innocua $\left(10^{4} \mathrm{cfu} / \mathrm{ml}\right)$.

similar phenomenon (QS cross-talk) may be occurring in mixed cultures of Listeria spp., although probably by a different type of quorum compound (<http://www.nottingham.ac.uk/quorum>/; accessed 15/04/09).

Nevertheless, it would also be important to evaluate the growth of each strain of $L$. monocytogenes in the presence of $L$. innocua_2030c to improve knowledge of this inhibitory effect.

L. monocytogenes_1339 with L. innocua_11288. In all the cases (mixture 2), no significant differences in the cell number of L. innocua_11288 was observed when L. monocytogenes_1339 was present $(P>0.05$; Fig. 3$)$. Except in the condition $5\left(10^{4}\right.$ L. monocytogenes: $10^{2}$ L. innocua), L. monocytogenes_1339 was significantly inhibited in the presence of L. innocua $(P<0.05$; Fig. 3$)$. The higher reduction rate $(5.69 \mathrm{log})$ was shown when the initial concentrations of L. innocua_11288 and L. monocytogenes_1339 were $10^{4} \mathrm{cfu} / \mathrm{ml}$ and $10^{2} \mathrm{cfu} / \mathrm{ml}$ respectively (condition 3 ), Thereby, the inhibition of L. monocytogenes_1339 was dependent on the initial concentration of L. innocua_11288.

L. monocytogenes_1340 with L. innocua_11288. The significant inhibition of $L$. monocytogenes_1340 in the presence of $L$. innocua_11288 was only observed when its initial concentration was lower than the initial concentration of L. innocua_11288 (condition 4), with a final reduction of $5.01 \log (P<0.05$; Fig. 4$)$.

Again, no significant differences in the cell numbers of $L$. innocua_11288 were observed when $L$. monocytogenes_1340 was present $(P>0.05$; Fig. 4$)$.

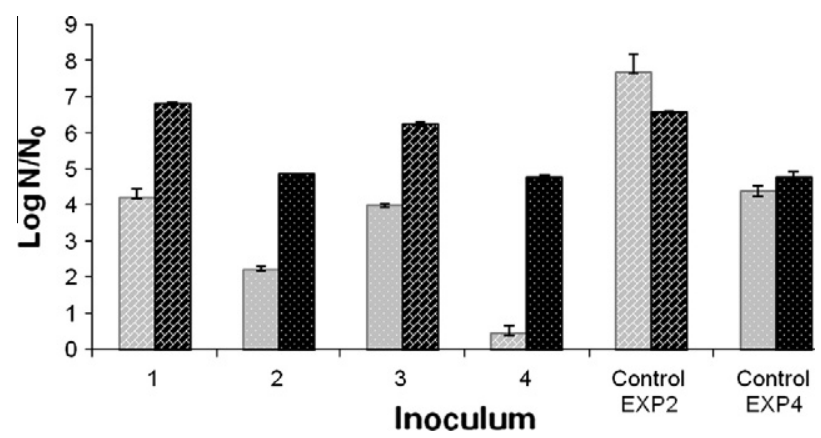

Fig. 3. Monitoring the number of viable cells in pasteurized milk: L. monocytogenes_1339 with L. innocua_11288. $\quad$ L. monocytogenes $\left(10^{2} \mathrm{cfu} / \mathrm{ml}\right)$; L. monocytogenes $\left(10^{4} \mathrm{cfu} / \mathrm{ml}\right) ; 8$ L. innocua $\left(10^{2} \mathrm{cfu} / \mathrm{ml}\right) ;$ L. innocua $\left(10^{4} \mathrm{cfu} / \mathrm{ml}\right)$.

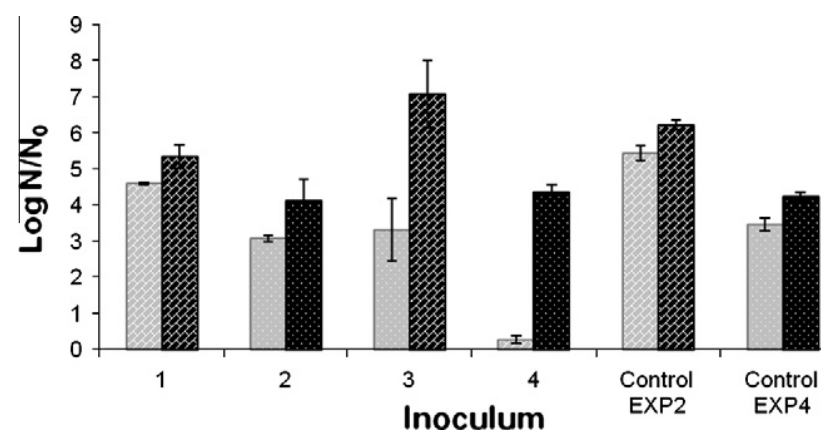

Fig. 4. Monitoring the number of viable cells in pasteurized milk: L. monocytogenes_1340 with $L$. innocua_11288. L. monocytogenes $\left(10^{2} \mathrm{cfu} / \mathrm{ml}\right)$; L. monocytogenes $\left(10^{4} \mathrm{cfu} / \mathrm{ml}\right) ; 3$ L. innocua $\left(10^{2} \mathrm{cfu} / \mathrm{ml}\right) ;$ L. innocua $\left(10^{4} \mathrm{cfu} / \mathrm{ml}\right)$.

The inhibition of $L$. monocytogenes by $L$. innocua undergoing enrichment culture as well as in growth in TSB-YE, only occurred after $24 \mathrm{~h}$ because following this time microorganisms are in more hostile conditions and consequently cells become more sensitive and easily inhibited. However, in TSB-YE only L. monocytogenes_1339 was inhibited by L. innocua_11288. This is a non-selective medium and consequently more favourable to growth than a selective medium

Besse et al. (2005) concluded that $24 \mathrm{~h}$ of incubation in Fraser broth was sufficient to attain the maximum population level in contrast to the current practice of $48 \mathrm{~h}$ and this suggested that Fraser enrichment can be reduced by $24 \mathrm{~h}$ in order to decrease the effected inhibition by L. innocua of some strains of L. monocytogenes. In fact, some of our results show a significant reduction in viable numbers of $L$. monocytogenes after $24 \mathrm{~h}$ of growth in Fraser broth in the presence of $L$. innocua, which could result in difficulties in detecting the presence of the pathogen. However, when levels of contamination are lower than the tested concentrations, $24 \mathrm{~h}$ in Fraser enrichment might not be long enough to reach the maximum population level which could lead to a false negative result for L. monocytogenes presence, since enrichment favours the nonpathogenic L. innocua. Therefore, it would be important to evaluate lower levels of contamination to improve knowledge about this possibility.

\section{Detection of inhibitory activity produced by Listeria strains}

Many authors (Besse et al., 2005; Kalmokoff, Daley, Austin, \& Farber, 1999; Yokoyama et al., 2005) demonstrated that Listeria species may produce inhibitory compounds such as bacteriocins that are active against other Listeria isolates. However in this study no inhibitory activity of $L$. innocua against $L$. monocytogenes or $L$. monocytogenes against $L$. innocua was observed in the spot-onlawn assays. These results can be explained because the majority of inhibitors represent defective bacteriophage particles. Therefore, production of bacteriocins was not the factor that explains the inhibition.

\section{Conclusion}

A relatively few mixtures of strains were tested, but it was enough to conclude that there was a high heterogeneity in the strains' behaviours. Overall, the inhibition of $L$. monocytogenes by L. innocua was always observed when the first one was initially present in lower concentration numbers. However it was also possible to observe the inhibition of $L$. innocua when a cocktail of $L$. monocytogenes was present in higher inoculum concentration. A possible explanation for this could be the phenomenon of quorum sensing. Growth inhibition by quorum sensing molecules has been 
reported for several organisms (<http://www.nottingham.ac.uk/ quorum>/; accessed 15/04/09).

The inhibition of $L$. monocytogenes by L. innocua is frequently related to the decrease in the growth rate of the strain inhibited or to the inhibitory activity caused by bacteriocins. In this study, however, these possible causes were not verified. Other explanations previously described, such as production of bacteriophages (Cornu et al., 2002; Kalmokoff et al., 1999), defective bacteriophage particles (Curtis \& Mitchell, 1992; Zink et al., 1995), or possession of a prophage (rendering the 'infected' strain 'immune' to a lytic phage), or a higher degree of fitness of one strain (Curiale \& Lewus, 1994; Beumer et al., 1996), were not investigated but could explain the results obtained.

Further experiments with a much broader number of isolates are required to better characterize these interactions, and also to determine the causes of inhibition of some strains by others.

\section{Acknowledgment}

This work was supported by FCT PTDC/AGR-ALI/64662/2006.

\section{References}

Albano, H., Pinho, C., Leite, D., Barbosa, J., Silva, J., Carneiro, L., et al. (2008). Evaluation of a bacteriocin-producing strain of Pediococcus acidilactici as a biopreservative for "Alheira", a fermented meat sausage. Food Control, 20 $764-770$.

Anonymous. (2004). Microbiology of Food and Animal Feeding Stuffs - Horizontal Method for the Detection and Enumeration of Listeria monocytogenes. ISO 11290-1: 1996/Amd.1:2004(E), International Organization for Standardization, Geneva.

Besse, N. G., Audinet, N., Kérouanton, A., Collin, P., \& Kalmokoff, M. (2005). Evolution of Listeria populations in food samples undergoing enrichment culturing. International Journal of Food Microbiology, 104, 123-134.

Beumer, R. R., Giffel, M. C., Anthonie, S. V. R., \& Cox, L. J. (1996). The effect of acriflavine and nalidixic acid on the growth of Listeria spp. In enrichment media. Food Microbiology, 13, 137-148.

Cornu, M., Kalmokoff, M., \& Flandrois, J. P. (2002). Modelling the competitive growth of Listeria monocytogenes and Listeria innocua in enrichment broths. International Journal of Food Microbiology, 73, 261-274.

Curiale, M. S., \& Lewus, C. (1994). Detection of Listeria monocytogenes in samples containing Listeria innocua. Journal of Food Protection, 57, 1048-1051.

Curtis, G. D. W., \& Mitchell, R. G. (1992). Bacteriocin (monocin) interactions among Listeria monocytogenes strains. International Journal of Food Microbiology, 16(4), 283-292.

Davies, E. A., Bevis, H. E., \& Delves-Broughton, J. (1997). The use of the bacteriocin, nisin, as a preservative in ricotta-type cheeses to control the food-borne pathogen Listeria monocytogenes. Letters of Applied Microbiology, 24, 343-346.

Eijsink, V. G. H., Skeie, M., Middelhoven, P. H., Brurberg, M. B., \& Nes, I. F. (1998) Comparative studies of class Ila bacteriocins of lactic acid bacteria. Applied and Environmental Microbiology, 64, 3275-3281.
Eppert, I., Valdés-Stauber, N., Götz, H., Busse, M., \& Scherer, S. (1997). Growth reduction of Listeria spp. caused by undefined industrial red smear cheese cultures and bacteriocin-producing Brevibacterium linens as evaluated in situ on soft cheese. Applied and Environmental Microbiology, 63, 4812-4817.

Farber, J. M., \& Peterkin, P. I. (1991). Listeria monocytogenes, a food-borne pathogen Microbiology Reviews, 55, 476-511.

Grau, F. H., \& Vanderlinde, P. H. (1992). Occurence, numbers and growth of Listeria monocytogenes on some vacuum-packaged processed meats. Journal of Food Protection, 55, 4-7.

Horáková, K., Greifová, M., Seemannová, Z., Gondová, B., \& Wyatt, G. M. (2004). A comparison of the traditional method of counting viable cells and a quick microplate method for monitoring the growth characteristics of Listeria monocytogenes. Letters of Applied Microbiology, 38, 181-184.

Kalmokoff, M. L., Daley, E., Austin, J. W., \& Farber, J. M. (1999). Bacteriocin-like inhibitory activities among various species of Listeria. International Journal of Food Microbiology, 50, 191-201.

Lebek, G., Teysseire, P., \& Baumgartner, A. (1993). A method for typing Listeria monocytogenes strains by classification of listeriocins and phage receptors Zentralblatt fur Bakteriologie, 278, 58-68.

MacDonald, F., \& Sutherland, A. D. (1994). Important differences between the generation times of Listeria monocytogenes and Listeria innocua in two Listeria enrichment broths. Journal of Dairy Research, 61, 433-436.

Mead, P. S., Slutsker, L., Dietz, V., McCaig, L. F., Bresee, J. S., Shapiro, C., et al. (1999) Food-related illness and death in the United States. Emerging Infectious Diseases, 5, 607-625.

Muriana, P. M. (1996). Bacteriocins for control of Listeria spp. in food. Journal of Food Protection Supplement, 54-63.

Norton, D. M., McCamey, M. A., Gall, K. L., Scarlett, J. M., Boor, K. J., \& Wiedmann, M. (2001). Molecular studies on the ecology of Listeria monocytogenes in the smoked fish processing industry. Applied and Environmental Microbiology, 67(1), 198-205.

Ortel, S. (1989). Listeriocins (monocins). International Journal of Food Microbiology, 8, 249-250.

Petran, R. L., \& Swanson, K. M. J. (1993). Simultaneous growth of Listeria monocytogenes and Listeria innocua. Journal of Food Protection, 56, 616-618.

Schlech, W. F. (2000). Foodborne listeriosis. Clinical Infection Diseases, 31, 770-775.

Seeliger, H. P. R., \& Jones, D. (1986). Bergey's Manual of Systematic Bacteriology ( $p$ p. 1235-1245). Baltimore: Williams and Wilkins.

Siegman-Igra, Y., Levin, R., Weinberger, M., Golan, Y., Schwartz, D., \& Samra, Z. (2002). Listeria monocytogenes infection in Israel and review of cases worldwide. Emerging Infectious Diseases, 8, 305-310.

Song, H. Y., \& Richard, J. (1997). Antilisterial activity of three bacteriocins used at sub minimal inhibitory concentrations and cross-resistance of the survivors. International Journal of Food Microbiology, 36, 155-161.

Vigonolo, G., Fadda, S., De Kairuz, M. N., Holgado, A. P. De R., \& Oliver, G. (1998). Effects of curing additives on the control of Listeria monocytogenes by lactocin 705 in meat slurry. Food Microbiology, 15, 259-264.

Winkowski, K., Crandall, A. D., \& Montville, T. J. (1993). Inhibition of Listeria monocytogenes by Lactobacillus bavaricus MN in beef systems at refrigeration temperatures. Applied and Environmental Microbiology, 59, 2552-2557.

Yokoyama, E., Maruyama, S., Katsube, Y., \& Mikami, T. (2005). Influence of bacteriocin-like substance, generation times, and genetic profiles of Listeria innocua on the isolation of Listeria monocytogenes. Comparative Immunology and Microbiology Infection Diseases, 1, 10.

Zink, R., Loessner, M. J., \& Scherer, G. (1994). Supplementary Listeria-typing with defective Listeria-phage particle (monocins). Letters of Applied Microbiology, 9 99-101.

Zink, R., Loessner, M. J., \& Scherer, S. (1995). Characterization of cryptic prophages (monocins) in Listeria and sequence analysis of a holin/endolysin gene. Microbiology, 141, 2577-2584. 